\title{
Culture-specific notions of causation in Matses grammar
}

David W. Fleck

\section{(2) OpenEdition \\ 12 Journals}

Electronic version

URL: http://journals.openedition.org/jsa/1959

DOI: 10.4000/jsa.1959

ISSN: 1957-7842

Publisher

Société des américanistes

Printed version

Date of publication: 1 January 2001

Number of pages: 177-196

ISSN: 0037-9174

\section{Electronic reference}

David W. Fleck, "Culture-specific notions of causation in Matses grammar », Journal de la société des américanistes [Online], 87 | 2001, Online since 27 February 2006, connection on 19 April 2019. URL http://journals.openedition.org/jsa/1959; DOI : 10.4000/jsa.1959 


\title{
CULTURE-SPECIFIC NOTIONS OF CAUSATION IN MATSES GRAMMAR ${ }^{1}$
}

\author{
David W. FLECK *
}

This paper looks at the linguistic coding of a typologically unusual type of causation in Matses, a Panoan language spoken in Amazonian Peru and Brazil. Specifically, the topic is the nominalizing suftix -anmës, whose function can be defined as specifying that : " the referent of the nominalization is an entity that non-volitionally, invisibly and of ten mysteriously causes helpless victims to enter some undesirable, enduring state. " This notion of causation appears to be particular to the Matses, suggesting that in addition to putative universal notions of causation, culture-specific notions of causal understanding should be taken into consideration in linguistic description.

KeY words : causation, Matses, Panoan, Amazonia, linguistic relativity.

\section{Conceptos de causalidad culturalmente especificos en la gramática del matsés}

Este artículo examina la codificación lingüística de una categoría de causalidad en matsés - una lengua pano hablada en la Amazonia peruana y brasileña - poco común en las demás. El tema específico es el sufijo nominalizador -anmës, cuya función puede definirse de la manera siguiente : el referente del proceso de nominalización es una entidad que, de manera involuntaria, invisible y a menudo misteriosa, causa que víctimas sin defensas entren en un estado no deseado y duradero. Este concepto de causalidad parece ser propio de los matsés y sugiere que, aparte de putativas universales, conceptos de causalidad específicos de una cultura deben ser tomados en cuenta en la descripción lingüística.

PALABRAS CLAves : causación, matsés, familia pano, Amazonia, relatividad lingüística.

\section{Une notion culturellement construite : la causalité en grammaire matses}

Cet article présente l'encodage d'un des causatifs du matses — langue de la famille pano parlée en Amazonie péruvienne et brésilienne — typologiquement peu courant dans les langues du monde. Le thème en est le suffixe nominalisateur -anmës que l'on peut définir ainsi : le référent auquel s'attache ce nominalisateur est une entité qui, de façon non intentionnelle, invisible et généralement mystérieuse, est la cause d'un état non désiré et durable pour le patient

* Department of Linguistics, Rice University, P. O. Box 1892, Houston, Texas 77251-1892, U.S.A.

Journal de la Société des Américanistes, 2001, $87:$ p. 177 à 196. Copyright $\bigcirc$ Société des Américanistes. 
sans défense. Ce type de causalité apparaît comme particulier à la langue et à la culture matses et suggère qu'en sus des universaux proposés dans ce domaine, des notions culturellement spécifiques relatives à la causalité doivent être prises en considération dans la description linguistique.

Mots CLÉs : causalité, Matses, Pano, Amazonie, relativité linguistique.

\section{INTRODUCTION}

One good way to gain popularity among the old Matses men is to make fun of the foods that non-Matses eat. I tried to elicit a laugh during one of these conversations : hoping to say, « Beans give you gas », I blurted out ${ }^{2}$ :

(1)

$$
\begin{array}{ll}
\text { podoto tsipis-me-quid } & n e-e-c \\
\text { bean fart-Caus-Agt.Nzr be-Npast-Indic } \\
\text { «Beans are ones that order you to fart. » }
\end{array}
$$

But the only response I got was puzzled looks. Until one old man said :

(2)

$\begin{array}{llll}\text { tsipis-anmës } & \text { ai podoto } & \text { tsipis-anmës } & \text { ne-e-c } \\ \text { fart-Causer.Nzr yes bean fart-Causer.Nzr } & \text { be-Npast-Indic } \\ \text { "Ones that make you flatulent ? Yes, beans are ones that make you flatulent. » }\end{array}$

Then everyone nodded and smiled, but the timing of the joke had been spoiled and no one actually laughed. And I wasn't even sure if their smiles were in response to my joke or to my latest misuse of their language.

Despite my temporary embarrassment, I was intrigued by this formation because I had previously seen the ending ammës only on three Matses words, all names for plants or animals, and so I had assumed it was not synchronically segmentable. Upon further inquiry with Matses speakers, I found that indeed -ammës was used productively as a nominalizing suffix, but only with a surprisingly small number of verb stems - from a list of 400 verbs roots, only 12 (3\%) were accepted by Matses speakers as suffixable with -anmës. But more remarkable than its limited distribution was the nature of the events that this suffix coded : all the situations involved causation events, but based on causal relations that people from non-Matses societies would likely consider odd, implausible or superstitious. The fact that -anmës is used productively to code a limited range of situation types centered around the Matses belief that animals, plants, and inanimate objects can cause humans to undergo unwanted physical changes without any physical contact, suggested that this might be an instance of a culture-specific notion being coded in a grammatical morpheme. That culture is reflected in language is perhaps uncontested with respect to vocabulary ${ }^{3}$, but there is some controversy about whether culture-specific beliefs are ever encoded in grammar. And so, the goal of this paper is to elucidate the meaning of the nominalizing suffix -anmës and to explore whether it does in fact code a non-universal type of causation. 


\section{The Matses and the Matses language}

The Matses (formerly known as Mayoruna; Panoan language family) are an indigenous Amazonian group consisting of about 1500 persons living along the Yavarí (Javari) River and its tributaries in Peru and Brazil. They made first peaceful contact with the national culture in 1969. The majority of the Matses continue to meet all their nutritional needs through traditional subsistence activities, including hunting, fishing, trapping, horticulture, and collection of wild foods. In Peru, about $80 \%$ are still essentially monolingual, but most young people have begun to learn Spanish and are eagerly adopting the national culture. The group of Matses from whom I learned most of the details about causative constructions live in the Matses village of Nuevo San Juan, on the Gálvez River in Peru. Nuevo San Juan has a total population of only 43 persons, all of whom are related by blood or marriage. See Fleck and Harder (2000) for details about the physical and biological setting of Nuevo San Juan; and see Erikson (1994) and Romanoff (1984) for information on Matses culture and history.

Matses is a dominantly agglutinating and primarily suffixing language with a preferred SOV constituent order; but word order is relatively free, with grammatical relations differentiated by ergative-absolutive case marking and nominativeaccusative person agreement. Open classes include nouns, verbs, adjectives, and adverbs ; pronouns, postpositions, interrogatives and particles form closed sets. Transitivity is strictly grammaticalized in Matses, with all verb roots having a basic syntactic valence that can be altered only with overt valence-adjusting morphology. Noun and adjective roots may occur in predicate position by simply at taching verbal inflectional morphology, but verbs must take special nominalizing morphology to be treated morpho-syntactically as nouns. Nominalization is ubiquitous in the Matses language : it is the basis for relativization, and in some text genre, copular clauses with nominalizations are as common as active clauses. Nominalizing suffixes are numerous and include some with general meanings and global applicability, such as -quid " Agent Nominalizer », - aid « Patient Nominalizer" » and -te « Instrument Nominalizer », as well as more narrowly applicable ones with specific meanings, such as -sio " person who performs an action too much » and -ammës « Causer Nominalizer », the topic of this paper.

\section{SYNTACTIC EFFECTS OF NOMINALIZATION USING -anmës}

Syntactically, nominalizations with -ammës are rather different from canonical causation constructions (as described in Dixon [2000], for example) : in nominalizations with -ammës, the locus of the causal relationship is between the referent of the derived noun and the $S$ (subject of intransitive clause) or $O$ (object of transitive clause) argument of the verb stem. In other words, as in sample sentence (3b), the suffix - anmës expresses causation by introducing a causer-causee relationship between a newly-introduced participant (the " causer », the referent of the newly-created noun) and a patientive participant (the absolutive argument of the original verb, the "causee-patient ") 4 . This contrasts with how causation is coded in active clauses, where the locus of the causative relationship is between the A (subject of transitive 
clause) argument and the $\mathrm{O}$ argument(s) associated with a valence-increased stem, as in (3c).

(3a)

$$
\begin{aligned}
& \text { deibi- } \varnothing \text { casen-o-sh } \\
& \text { Davy-Abs become.thin-Past-3 } \\
& \text { « Davy got thin. » }
\end{aligned}
$$

$$
\begin{array}{lll}
\text { sedudi } & \text { casen-ammës } & n e-e-c \\
\text { armadillo } & \text { become.thin-Causer.Nzr } & \text { be-Npast-Indic }
\end{array}
$$

" Nine-banded armadillos are ones that make [people] get thin. »

(3c)
sedudi-n
deibi-Ø
casen-me-o-sh
armadillo-Erg Davy-Abs become.thin-Caus-Past-3
"The nine-banded armadillo made Davy get thin. »

In the -anmës constructions, the $\mathrm{S}$ or $\mathrm{O}$ argument of the original verb becomes generalized and is not mentioned overtly in the nominalized clause, but the body part of the affected entity may be stated overtly, either as a prefix or as a full noun preceding the verb. A further effect of nominalization with -ammës appears : if the verb codes a punctual event (e.g., to fart), the meaning of the caused effect becomes that of being in a state (e.g., being flatulent) rather than referring to a single instance of the event.

\section{POSSIBLE NOMINALIZATIONS USING -anmës}

There are three levels at which nouns formed with -anmës are integrated into the Matses language. They may be : (i) the name for a kind of plant, animal or illness ; (ii) a lexicalized, commonly used word that is not the name of any particular entity ; or (iii) a word that speakers have not heard before, but nonetheless judge as grammatically correct. All the verbs that I have found so far that can be nominalized with -ammës are listed in Figure 1. The nominalizations in Figure 1 include those nouns derived from the 12 verb roots from the list of 400 verbs mentioned above, plus 7 other nominalizations with -anmës that were encountered by less systematic means. Below I will describe all the nominalizations listed in Figure 1 to various degrees of detail so that the reader can get a feel for the nature of the causative situations that these constructions code.

The term shëcmaucudanmës (tooth-fall.out-Causer.Nzr) « one that causes teeth to fall out ", is the only lexicalized name for Hyospathe elegans and Chamaedora pinnatifrons, two morphologically similar understory palms. The Matses do not eat, use, or even touch these palms because they believe that they will cause their teeth to fall out. When Matses are asked how it is that these palms make one's teeth fall out, they reply that it is not presently known whether it is eating the fruits, eating the hearts, using them for the construction of artifacts or shelters, or just touching them that causes one's teeth to fall out. They say that many generations ago people knew exactly how and why these palms made teeth fall out, but now people just know that they make one lose their teeth somehow and that it is best to just avoid shëcmaucudanmës. It might be said that the traditional knowledge or belief concerning shëcmaucudanmës has 


\begin{tabular}{|c|c|c|c|c|}
\hline \multicolumn{5}{|c|}{ Lexemes that are names or parts of names of plants, animals or illnesses: } \\
\hline \multicolumn{5}{|c|}{$\begin{array}{l}\text { Lexemes that are names or parts of names of plants, anımals or illnesses: } \\
\text { shëc-maucud-anmës tooth-fall.out-Causer.Nzr 'one that causes teeth to fall out' (palm) }\end{array}$} \\
\hline dachi-anmës & curse.to.die-Causer.Nzr & & & a future death' (palm tree \\
\hline uen-anmës & feel.ce & " & " & chills' (fish) \\
\hline$s$ & inflate-Causer.Nzr & 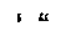 & " & y to swell' (fis \\
\hline & ar.Nzr & s & " & \\
\hline 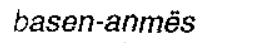 & & ra & " & ins'(dis \\
\hline ës & & s & " & \\
\hline ist & & & " & \\
\hline \multicolumn{5}{|c|}{ Nominalizations that are lexicalized words, but not names: } \\
\hline ën-anmës & hurt-Causer.Nzr & \multicolumn{3}{|c|}{ 'one that causes one's $X$ to hurt' } \\
\hline ës & Nzr & & & one to get thin' \\
\hline id & & & " & one \\
\hline nës & & & “ & hai \\
\hline ipis & & & & \\
\hline ënẽs & d & & “ & dec \\
\hline \multicolumn{5}{|c|}{ are grammatically acceptable, but not lexemes: } \\
\hline êun-anmës & tear-Causer.Nzr & \multicolumn{3}{|c|}{ 'one that causes one's eyes to tear up' } \\
\hline en. & & & & \\
\hline n-a & $\mathrm{N} 2$ & ‘ " & “ & uncontrollable urination' \\
\hline & & ' & " & than \\
\hline hcas-anme & cetpy-vauset & . & “ & \\
\hline
\end{tabular}

FIG. 1. - Summary of all-ammës nominalizations found in this study

been forgotten, but some of this lore is retrievable by linguistic analysis of the term by the Matses ${ }^{5}$.

This term can also be used to refer to anything that a speaker believes will make teeth fall out. Traditionally, the Matses believe that sting ray, monkey and peccary (pig-like mammals) livers and curassow (large game birds) gizzards are shëcmaucudammës. Recently, I have heard Matses call frozen foods shëcmaucudammës, not as a result of any actual tooth loss, but rather because it makes their teeth feel as if they will surely fall out (ex. 4).

(4)

$\begin{array}{lll}\text { che-te dauëbud-quio-ic-quid } & \text { che-temaid } & \text { ne-e-c } \\ \text { eat-Inst.Nzr cold-Aug-be-Agt.Nzr } & \text { eat-Neg.O.Nzr } & \text { be-Npast-Indic }\end{array}$

"Ice cream is one that is not good for eating. "

shëcmaucudanmës-en

ne-chit-e-c

one.that.makes.one's.teeth.fall.out-Contrast be-Uncert-Npast-Indic

"It's probably one that makes your teeth fall out. »

The term shëcmancudanmës cannot refer to a person who makes you eat something that makes your teeth fall out; it can only be a thing.

Another lexicalized nominalization with -ammës that is surrounded by cultural beliefs is dachiammës (curse.to.die-Causer.Nzr) " one that causes a future death. » There is a folk variety of the palm tree species Oenocarpus bataua, whose only 
lexicalized name is isan dachiammës. The term isan is the name for the more common variety of $O$. bataua, a very abundant, tall, upland forest palm that the Matses use for many subsistence purposes, not least of which is to make a much appreciated drink from the ripe fruits. The variety of $O$. batana called isan dachiammës is almost identical to the common isan, except, according to the Matses, its fruits are abnormal (larger; smaller, or not uniformly ellipsoid), the trunk is thinner and shorter, and its leaflets are wider and more closely spaced along the rachis. It is not certain if there is a biological basis for this distinction or if this is an instance of « overdifferentiation » (Fleck et al. 1999), but the Matses certainly consider it an important distinction as they consistently avoid isan dachiannës palms believing that if one accidentally makes a drink from the fruits and drinks it (i.e., unwittingly confusing isan dachiammës for isan), some close relative of the person who drank it will die in the near future. The Matses belief is not that isan dachianmës (or the other things called dachianmës described below) is just a harbinger of death, but that it will actually cause it. There is no way to know who it is that will die, but it won't be the person who drank it. The person who drank the isan dachiammës drink may get blamed when someone dies, but he or she would not be referred to as dachianmës, even if they were hypothetically evil and drank it intentionally just to see a death.

If a Snowy Egret, which is normally diurnal, flies over the village singing at night, the Matses rush outdoors to see in which direction the egret is flying. They do this because that particular egret is a dachiammës : as a result of its nocturnal singing, someone in a Matses village that occurs in the direction that the egret is coming from will die within a period of about two months. If a dog gets up on the roof of a house and starts to howl (no one is sure how dogs get up there), then this also produces a future death, and often results in the dog getting shot for being a dachiammës. The giant armadillo is considered to be a dachianmës animal - if it digs up the ground right on a path or in an old hunting camp, it causes a future death. Accidentally stepping on the giant armadillo's diggings make the impending death even more certain. To dream of a vulture also assures an impending death, and the dream or the vulture may be called dachiammës, but not the dreamer. One does not need to wait for someone to die to call something dachianmës - people already know that someone will die when isan dachiannës is drunk, when a Snowy Egret flies by singing at night, etc.

The term iquenanmës (feel.cold-Causer:Nzr) " one that causes chills » is the only lexicalized name for a small species of needlefish (family Belonidae). According to the Matses, if one eats or even touches this species of fish, he or she will get chills every time it rains. The person would not get the chills right away, but only after weeks or months ; and the chills could last for years. These chills do not occur during a hot day, when one might welcome a chill, but only in inclement weather, when one would prefer to feel warm. So someone would not touch an iquenammës fish on purpose in hopes of obtaining personal internal air conditioning. The Matses do not eat this species of fish, of course, and they do not have to worry about it getting on their hooks, because it is a very small fish with a very small mouth. It is encountered regularly, however, while fishing with fish poisons, a time when one must be careful not to come in contact with iquenammës while collecting the edible species. The three-day long cold spells that hit Matses territory in June and July (caused by seasonal Patagonian storms) are 
called suc and sometimes referred to as iquenammës. These cold and windy spells are considered somewhat mysterious and unpleasantly very cold.

Another kind of fish to avoid is the one called poccammës (inflate-Causer.Nzr) " one that causes one's belly to swell." This is the only name for a small species of catfish with a prominently bloated (inflatable) abdomen that can cause people, especially children, to be continuously insatiably hungry and eat too much (potentially eventually making their bellies « inflate »). The effect can persist for years.

Yet another nasty fish is dësbuanmës (get.pimples-Causer.Nzr) « one that causes pimples. " According to the Matses, if one eats or touches this small species of armored catfish, they get pimples of a certain kind all over their body. This condition can recur throughout a person's life unless treated with a leaf infusion of a certain plant.

Unlike the above words, basenammës (have.pain-Causer:Nzr) « one that causes abdominal pains " is not the name for a biological taxon, but rather for what might be called an illness. When one has sharp intermittent abdominal pains, one says that it is caused by basenammës. In the Matses belief system, almost all maladies are caused by taboo animals or jungle spirits, but this one is different in that, according to the Matses, it does not have any identifiable tangible or understandable causer. One simply gets these pains when basenammës causes them. The absence of a concrete referent for this term makes one wonder whether there was a biological organism with a restricted geographic range in the Matses' ancestral territory named basenammës. The term basenammës can also be used to refer to a fish called dëuisac " elongated nose » or to kingfishers which, if eaten or touched, can cause people to get stomach cramps that feel like a sharp point (like this fish's rostrum or the kingfisher's beak) is poking at their abdomen. One speaker suggested that lettuce might be correctly referred to as basenammës because it probably causes stomach aches to non-Matses, who take delight in eating « leaves » and other non-human food.

The term occasadammës (have.nausea-Causer.Nzr) « one that causes nausea » refers to a species of tree (family Leguminosae) which, according to the Matses, causes nausea for most of the day if one eats its fruits or touches it and then doesn't wash his / her hands before eating. The term occasadammës is also sometimes used to talk of things like rotting flesh or perfume.

There is a plant that can ruin one's eyesight when one touches it or consumes food, beverages, or tobacco contaminated with it. Its name is bëshuanmës (become.blindCauser.Nzr) « one that causes bad eyesight. » A woman's vulva can be bëshuanmës if a man looks directly at it, and men with bad eyesight are often accused of having looked at a woman's vulva. Also, the eggs of certain edible frogs, which may be in the captured frog's abdomen, are bëshuammës if one eats them. Two-toed sloth spleens can also be referred to with this term because they can cause blindness or bad eyesight to those who dare to eat it.

There is a small bird called acte chonchon that is often referred to as ëshë nënanmës (eye hurt-Causer.Nzr) « one that causes one's eye to hurt. » The term ëshë nënammës, considered a synonym of acte chonchon by some speakers, reflects the Matses belief that if one looks at this passerine, their eye will start to hurt later on. The term nënammës can also be used to describe other things that make a part of one's body hurt, as in (5) : 
(5)

$\begin{array}{lll}\text { chotac-n pete pucu nënammës } & n e-e-c \\ \text { nonMatses-Gen food stomach one.that.makes.X.hurt } & \text { be-Npast-Indic } \\ \text { "Mestizos' food is a thing that makes one's stomach hurt. » }\end{array}$

The Matses believe that nine-banded armadillos cause one to get thin when one eats their meat, handles them or even looks at one too long. If a man touches or looks at one in the forest, his wife or young children could also become thin as a result. The term, casenanmës (get.thin-Causer.Nzr) « one that causes one to get thin » is not the name for this armadillo (its Matses name is sedudi), or even a synonym for it, but rather a term that is often used to talk about it. Accordingly, nine-banded armadillos are dietary taboos for Matses, but only for young people - old people may eat them, if they wish, Matses tell me, since old people are already thin, and if they aren't, it wouldn't much matter if they got thin, anyway ${ }^{6}$. Acouchies (a rat-sized rodent), squirrels, large armored catfish, and a species of frog, are in this same category and are commonly referred to as casenanmës. The Matses also believe that if you eat dirt, you will become thin, and so Matses caution kids not to eat dirt or dirty things because dirt is casenanmës. Intestinal parasites could be casenanmës, but are not usually referred to thus.

The Matses believe that all animals and some species of trees can cause a person to become ill. Rare, non-game mammals like jaguars, tayras (dog-like mammals), capybaras (giant rodents), and pygmy anteaters are especially dangerous, while game animals and trees are not so dangerous. If a man sees or touches the more dangerous animals while he is in the forest, his wife, children or he himself could get sick. The less dangerous animals are hazardous only to the man's unborn or very young children. A recently born baby could get sick and die and a pregnant wife's unborn baby could be born deformed (supposedly taking on animal-like properties). The belief is that spirits associated with these animals are what induce the illness, and these conditions (except deformity) can be treated with infusions of the leaves of the plant species that «belong » to the animals that made the person sick. These animals can be referred to with the term cuidammës (enchant-Causer:Nzr) « one that causes one to get sick. » My gloss of cuid, "enchant », is an inexact one because unlike the English term, the Matses term cannot refer to the action of shamans making people sick. Furthermore, there is no sense in which the animals or plants themselves have any intention of hurting people, and the motivations and methods of their associated spirits are at best uncertain.

Anything that makes one's hair fall out could be called maocudanmës (fall.outCauser.Nzr) " one that causes hair to fall out ", but there is one thing in particular that is always called to mind by this word. There is a shampoo that is commercially available in most rural stores which, according to the Matses, makes one's hair fall out. This is obviously not an old belief, but many Matses now believe this. And they find it an object of much irony and mystery, as they know that the shampoo is produced specifically for the benefit of people's hair.

The Matses report that eating swamp palm fruits (Mauritia flexuosa) causes flatulence, and they often comment upon this with the term tsipisanmës (fartCauser.Nzr) « one that causes flatulence. » The mysterious thing about this causal relation is that the swampy ground at the base of swamp palms becomes foamy when 
it is littered with fallen ripe fruit, and this foam is implicated in the causal connection. Beans, which are now given to the Matses by a government aid program, inevitably end up being tossed in the river because they are tsipisammës. A person who makes one eat beans, however, cannot be referred to as tsipisammës.

Several species of small plants and a species of epiphyte (an arboreal plant) are considered to be uënësanmës (die-Causer-Nzr) « one that causes one to die. » Matses are on the lookout for these plants while clearing undergrowth prior to felling trees for making a swidden because if one touches one of these plants or hangs around the area where one of these plants has been cut with a machete, that person will simply die. Also, many Matses believe that some Western medicines, rather than heal, will make one die. Weapons and concocted poisons, however, cannot be referred to as uënësan$m e ̈ s$, because they are instruments used by a causer (the killer) rather than ultimate causes of death ${ }^{7}$.

The following words, constructed by me, were judged as grammatically acceptable by at least two Matses consultants, but they could not remember having heard them before. One is bëtnammës (tear-Causer:Nzr) " one that causes eyes to tear up. " An onion, for example, could be bëtmanmës. Paca (a dog-sized rodent) fat could be referred to as pienanmës (to.diarrhea-Causer.Nzr) « one that causes diarrhea ", particularly in reference to my first experience eating paca fat. A shaman could make someone get diarrhea, but he would not be called pienanmës. Beer could be called istmanmës (urinate-Causer.Nzr) "one that causes uncontrollable urination", because, even though one can normally hold his pee, when he drinks a lot of beer he cannot escape eventually having to go relieve himself continually. After seeing the effects of the sun on my skin, several Matses speakers agreed that the sun might appropriately be referred to as bishuccudanmës (peel-Causer:Nzr) « one that causes one's skin to peel. » A boring movie, especially one with subtitles, could be ushcasanmës (feel.sleepy-Causer.Nzr) " one that causes sleepiness. » These novel usages of -anmës may seem less odd to non-Matses, but the Matses speak of all these as topics of great irony and/or mystery. For example, onions (new to the Matses) have an undesirable effect on those who cut them, yet people in cities and towns actually pay money to acquire them. And the observation that televisions are purchased at great expense and attended regularly by non-Matses to apparently bore themselves hours on end staring at undulating two-dimensional images is a source of much merriment for older Matses. Several of these nonce words were discussed in the towns of Colonia Angamos and Iquitos, where novel usages of -anmës seemed most appropriate for describing phenomena foreign to Matses traditional culture.

\section{RESTRICTIONS ON THE USE OF -ammës}

In the course of uncovering the -ammës nominalizations described above, many verb roots that were quite similar in meaning to those listed in Figure 1, were rejected as nominalizable with -ammës. It should be noted that there was little debate as to the grammaticality of (plant, animal, and disease) names and other lexicalized terms, but there was much disagreement about what novel nominalizations with -anmës were possible. Similarly, there was some disagreement about what additional situations could be referred to using some of the widely accepted nominalizations. Thus, one 
may wish to discount or to treat these elicited data separately from the naturally occurring -anmës nominalizations. Nevertheless, the explanations given by the Matses for rejecting some nominalizations and accepting others provided considerable insight into the set of principles governing the set of verbs that could be suflixed with -anmës and the nature of the situations that could be referred to with these nominalizations. Below I present several attempted uses of -anmës that were consistently rejected, and I consider what they can tell us about the criteria governing the use of -anmës.

One restriction on the use of -anmës has to do with the volitionality of the causal event. An example that shows this clearly is the $\ddot{e} u$ ant, a tiny red ant that, according to Matses, bites people in the inner corner of their eye during the night, making them wake up in the morning with a sore eye ${ }^{8}$. Matses speakers tell us that the $\ddot{e} u$ ant cannot be referred to as ëshë nënanmës because the $\ddot{e} u$ ant bites one on purpose, while the acte chonchon / ëshë nënanmës bird (described in the preceding section), by contrast, has no interest in hurting a person. This seems to indicate that a restriction on the use of -anmës is that the causer must not be volitional with respect to the change in state undergone by the experiencer, even if it is an animate entity that is capable of performing other actions volitionally. Even with the verb isun « urinate», the only verb in the list (Figure 1) that involves volition, refers to entering a state of uncontrollable urination when suffixed with -anmës. The other intransitive verbs are all experiencer verbs (and therefore non-volitional), and the two transitive verbs (dachui " curse to die ") and (cuid « enchant »), despite my inexact English glosses, in fact refer to events that cannot be carried out on purpose (in contrast to typical transitive verbs). The fact that instruments such as arrows or concocted poisons could not be uënësanmës « one that causes death ", also implies that the requirement of the absence of volition is not just with respect to the entity being referred to by the nominalization, but rather the use of -anmës seems to require that the event itself not involve volition.

The verb shubi « cry » might be expected to take-anmës considering that it refers to an action that is often brought about non-volitionally. So why is it that the Matses reject *shubi-anmës (" one that makes one cry »), but accept bëtmanmës « one that causes one's eyes to tear up ? » The Matses' response to this is that one is expected to be able to control crying, but the watering of one's eyes is beyond one's control. This gives some insight into why it is that isun « urinate » can be nominalized with -anmës, but chimu « to defecate » cannot - the reason seems to be that there exists a term for uncontrollable defecation (pien " to diarrhea ") while there is no separate lexeme for uncontrollable urination. The nominalization, *mamën-ammës « laugh / smile / playCauser.Nzr ", also seems a likely word in Matses, but it is nonetheless consistently rejected by Matses speakers. The reason given for this is the same as that for " cry »: because laughing, smiling, and playing are actions over which a person has control. Even the word dacuëd « be scared » cannot be nominalized with -ammës because the Matses believe that one can control fear, and so it does not make sense to say *dacuëd-ammës. This requirement seems to respond not to whether one can actually control the action, but rather to whether the speaker believes that one should ideally have control over the action. This is a case in point of Malle's (to appear) warning that one must consider a society's folk theories in analyzing linguistic categories, rather than using one's own understanding of physiology, physics, psychology, philosophy, etc. 
The next apparent restriction on using -ammës is that the verb must either refer to a state or must be subject to an imperfective reading referring to an enduring state. This is evinced from the fact that all the-ammës nominalizations in Figure 1 refer to events of entering into an enduring state (e.g., flatulence, having diarrhea), even if the verb roots refer to punctual events (e.g., to fart, to diarrhea). This sheds light on why ucbud-anmës " vomit-Causer.Nzr 》 is regularly rejected while occasadanmës " one that causes one to be nauseous $»$ is a common word, both uncontrollable events that could be brought about by non-volitional causers. The catch here seems to be that nominalizations with -anmës only refer to events that involve entering into a somewhat enduring state, like nausea, rather than a quick violent event like vomiting. The one speaker who accepted ucbud-ammës said it might be used to refer to the acate tree toad (Phyllomedusa bicolor) or its skin toxin, which is used to induce ten-minute long bouts of vomiting. This might be considered a marginally enduring state. There are perhaps few verbs that cannot have an enduring state interpretation, but words like « vomit », which have enduring state counterparts like « be nauseous », are more susceptible to this restriction.

Another word that seems like it should be correct is *bëdan-anmës « get.betterCauser.Nzr », particularly in reference to something like a medicinal plant. A medicinal plant does not act with volition, recovery from an illness is not controlable, and being recovered can be construed as an enduring state. So why should *bëdan-anmës get the " thumbs down »? The Matses reply is that the effect of the causation event must be undesirable ${ }^{9}$.

One of the most common justifications for rejecting a nominalization with -anmës was that, " people wouldn't understand it. » This is a consequence of the requirement that all usages of -ammës involve both spatial and / or temporal separation between the causer and the caused event, and the absence of an intermediary participant or force, which entails that the causing action be always invisible and often mysterious. For example, *dauebud-anmës (cool.down-Causer.Nzr) was judged inappropriate for referring to an electric fan, because the fan was « right there. " So, because -anmës excludes contactive or obvious / visible cause-effect relationships, the (invisible) cause-and-effect relation will be obvious to the hearer only if it involves a shared cultural belief. For example, most Matses have not experienced smoking tobacco (they traditionally only consume tobacco as snuff blown through a tube by a second person), and so the term *toshoque-anmës (cough-Causer.Nzr) was rejected, even in reference to the long term effects of tobacco smoking. One speaker who had been told about the dangers of smoking explained that he and $I$ could use the term among ourselves if we wished, but most Matses would not consider it a word because they do not know about the effects of smoking and they do not consider anything to be capable of putting someone into an enduring state of coughing. A final telling rejected word is * tsitad-ammës (be.constipated-Causer.Nzr), which in reference to manioc flour (eaten in large quantities unaccompanied by other foods or beverages) seems to meet all the requirements : the manioc flower does not cause constipation volitionally, the patient does not have control over the event once s / he has eaten the flour, constipation can be an enduring state which is generally considered undesirable, and the causation event is temporally remote and invisible. But *tsitad-anmës was rejected because the cause-effect relationship was obvious and uninteresting. So although this 
is not a condition that is applied as consistently as others above, it seems that nominalizations with-anmës are more plausible if they involve a mysterious or ironic situation.

In summary, the five following properties are characteristic of all the attested uses of the causer nominalizer, -anmës :

i) the state must be brought about non-volitionally

ii) the verb must specify a state/ event over which humans have no direct control

iii) the event must involve entering an enduring state

iv) the effect must be undesirable

v) the event must be brought on by a remote, invisible, often mysterious cause

From the 19 (21) known possible nominalizations (Figure $1 \&$ endnote 7) and the rejected nominalizations described in this section, it is evident that distinctions such as transitive vs. intransitive, active vs. inactive, agentive vs. patientive or other readily recognized verb classifications cannot predict the set of verbs that may be used with -anmës. Similarly, no simple dichotomy of semantic causative event types can predict what events may be coded with -anmës. Rather, the set of verbs that can be nominalized with-anmës and the situations to which they can refer can only be predicted using all the five properties listed above.

It is unlikely that Matses speakers mentally consult such a list of properties when they consider novel uses of -anmës, but rather this list is probably an artifact generated by Matses post hoc justifications for rejecting or accepting uses of -anmës. Nevertheless, this list gives us some insight into the meaning of -anmës, a meaning that seems to be describable in English only in terms of a rather complex set of variables, with a definition of the specific function of -anmës reading something like : " the referent of the nominalization is one that non-volitionally, invisibly and often mysteriously causes helpless victims to enter some undesirable, enduring state. »

Another way of characterizing -anmës is to say that its basic meaning is « remote causation " : a cause-effect relation where the causer is spatially distant from the patient, and the causing event is temporally distant from the caused event. Remote causation contrasts with focused causation, where the causer and the patient (and therefore also the causee) are temporally and spatially proximate, and the causing and the caused events are viewed as a single, concurrent event. Other properties of -anmës nominalizations could be described as « abstractly remote ». For example, the causee is peripheralized by being generalized and not mentioned overtly ; the causer appears to have no interest in its victim, rather than being focused on the event; the time at which the state is entered into is difficult to pinpoint ; and control and understanding of the causation event are not accessible to affected participants. For me, the most interesting thing about the coding of remote causation by -ammës is that, in contrast to what I would expect of remote causative events, the causal relations coded by -anmës do not require an intermediary participant or force for the causal event and the resulting event to be spatially and temporally distant.

In sharp contrast to my difficulty in succinctly describing situations coded by the -anmës suffix, the Matses language can code them with a simple monomorphemic linguistic unit. Does this suggest that this type of causal relation is central and basic to Matses' way of thinking ? In the next section I will show that the linguistic evidence 
suggests that the types of events coded by -ammës represent a more important conception of causation to the Matses world view than the limited number of exemplars might suggest.

\section{COMPARISON WITH OTHER CAUSATIVE GRAMAAR IN MATSES}

The causative events described with -anmës certainly do not fit characterizations in linguistics of prototypical « humanly relevant causation » (Lakoff 1987, pp. 54-55) :

«Prototypical causation appears to be direct manipulation, which is characterized most typically by the following cluster of interactional properties :

1. There is an agent that does something.

2. There is a patient that undergoes a change to a new state.

3. Properties 1 and 2 constitute a single event; they overlap in time and space; the agent comes in contact with the patient.

4. Part of what the agent does (either the motion or the exercise of will) precedes the change in the patient.

5. The agent is the energy source ; the patient is the energy goal ; there is a transfer of energy from the agent to the patient.

6. There is a single definite agent and a single definite patient.

7. The agent is human.

8. a. The agent wills his action.

b. The agent is in control of his action.

c. The agent bears primary responsibility for both his action and the change.

9. The agent uses his hands, body, or some instrument.

10. The agent is looking at the patient, the change in the patient is perceptible, and the agent perceives the change.

Most of the properties governing the use of -ammës presented at the end of the preceding section, particularly properties (i), (ii), (iii), and (v), are in direct contrast to these interactional properties. Lakoff $(1987$, p. 55) claims that « the most representative examples of humanly relevant causation have all ten of these properties $»$ and that these prototype effects are relatively constant across languages. If this is indeed true, it leads us to conclude that -ammës codes a very non-prototypical type of causation in comparison with other languages. Even so, this type of causation appears to be an important, if not central concept in Matses thinking, a conclusion reinforced by two linguistic facts about -anmës described subsequently.

First, there is no lexeme, morpheme, or construction in the Matses language other than -ammës that codes causation exclusively. The Matses can and do talk about situations that could be described as " prototypical » causative events without using -anmës, but all other morpho-syntactic processes in the Matses language that can be used to describe causative situations either serve other functions in addition to coding causation, or are not true causative constructions as defined in the linguistics literature (e.g., Shibatani 1976). In Matses, causation can be coded as follows : morphologically, the verbal suffix -me codes event complexity, including causation, permission, enablement, and semantic promotion of instruments. There are transitive verb roots that could be described as entailing a causation event, but these are not treated morphosyntactically any differently from transitive verbs that do not contain causative 
notions in their meaning. As is common for agglutinating languages, causation is not coded in analytic (syntactic / periphrastic) constructions, but causative events can be related in two-verb constructions where an imperative command is quoted (as in, Bob told Jim, "Go! "), which in some cultural contexts strongly imply, but do not entail, the completion of the command. (Fleck [to appear] describes all these Matses causative constructions.)

The second linguistic pattern that suggests that -ammës is central is that while Matses grammar offers several ways to derive a noun that refers to a causer, -anmës is the only nominalizer that contains within itself the causative meaning. The other ways of accomplishing causer nominalizations require a combination of suffixes : the suffix sequences -me-quid (ex. 6) and-an-quid (ex. 7) can be attached to non-causative verbs to create nominalizations that refer to the causer of more prototypical causation events ${ }^{10}$.

(6)

tsipis-me-quid

fart-Caus-Agt.Nzr

« [person] that makes [someone] fart » [e.g., by ordering him to do so, by stepping on his stomach, or by giving him gas-inducing food]

(7)

tsipis-an-quid

fart-Antpass-Agt.Nzr

« [person or non-human] that causes [someone or people in general] to fart or

become flatulent $»$ [could be the gas-inducing food or the person who provided it]

(8)

tsipis-anmës

fart-Caus.Nzr

" [non-human entity] that causes [people in general] to become flatulent »

Meanwhile, the morphologically simplest construction type for introducing a causative meaning into a nominalization is accomplished by -anmës (ex. 8). We also note that those nominalizations coding more direct (= prototypical) causation are morphologically more complex - this is the opposite of the expected « iconic » association between direct causation and causative constructions exhibiting less grammatical material (Haiman 1983).

If we consider the nominalization of lexical causative verbs ${ }^{11}$ we see that there is another competing construction for the morphologically simplest causer nominalization : because lexical causative verbs already express a causative situation, they need only be suffixed with -quid " Agent Nominalizer » (which by itself does not impart a causative meaning) to become a nominal that refers to the causer of the event (ex. 9).
(9a) cues-quid kill-Agt.Nzr « killer»
(9b) shëctenamë nica-quid white-lipped-peccary make.run.off-Agt.Nzr " one that makes white-lipped peccaries run off »

Similarly, when we look at active clause constructions, we note that causativization with -me « Causative » requires no more morphological complexity than nominalization with -anmës; it is in nominalizations, such as example (6), that causative constructions with -me are more complex than with -anmës. 
It is instructive to look at the types of causation that lexical causative verbs and the suffix -me code in active sentences in terms of focused vs. remote causation (see the end of the preceding section for definitions of focused and remote causation) and mediated vs. unmediated causation (keeping in mind that these dichotomies actually just represent extremes in continua). Focused causation may occur with or without an intermediary ; in Matses, focused causation events that do not involve an intermediary (c.g., Bob killed Jim) are usually coded with lexical causative verbs. Focused causation events that involve an intermediary are usually coded by suffixation with -me, but these tend to be marginal because when an intermediary is involved, it is harder to picture the causing and the caused events as a single event. An English sentence like, Bob made Jim spill his drink (by pushing Jim) could be construed as a mediated focused event, but it is still possible to separate the causing event from the caused event despite their temporal synchrony. The suffix $-m e$ is actually more frequently used to code mediated remote events, where, consistent with ordinary notions of causal relations, an intermediary is expected to effect the separation between the causing event and the caused event. The intermediary may be an overtly stated participant (usually a causee) in the sentence representing a person (ex. 10) or an instrument (ex. 11) that allows the causer to be absent when the caused event takes place.

(10)

\begin{tabular}{|c|c|c|c|c|}
\hline $\begin{array}{l}\text { matses-n } \\
\text { Matses-Erg }\end{array}$ & $\begin{array}{l}\text { aton } \\
\text { 3Gen }\end{array}$ & $\begin{array}{l}\text { chido } \\
\text { woman }\end{array}$ & $\begin{array}{l}\text { titado } \\
\text { peach.palm }\end{array}$ & $\begin{array}{l}\text { sica-me-e-c } \\
\text { strain-Caus-Npast-Indic }\end{array}$ \\
\hline
\end{tabular}
(11)

$\begin{array}{llll}\text { matses-n } & \text { tiante-n } & \text { nëishamë } & \text { se-me-e-c } \\ \text { Matses-Erg } & \text { bamboo-Inst } & \text { tapir } & \text { pierce-Caus-Npast-Indic }\end{array}$

« Matses cause tapirs to get stabbed with bamboo-blade traps. »

The fourth logical possibility, unmediated remote causation, may sound impossible in that it involves a causer acting on a causee from a distance without any intermediary at all. In active constructions, Matses can code the few sanctioned cases of unmediated remote causation using -me, or with a few lexical causative verbs, such as cuid " enchant " and dachui "curse to die. » Figure 2a summarizes how these different types of causation are coded in active sentences. What strikes us when we compare active and nominalization causative constructions is that -anmës exclusively codes this most unusual type of causation, unmediated remote causation (Figure 2b).

\section{HOW DIFFERENT IS MATSES CAUSAL THINKING?}

What is one to make of this unmediated remote causation that the Matses language codes with -anmës? Upon reflection on this causal process, it seemed counterintuitive to me that something could have a causal effect on a remote entity, unless there was some type of intermediary, such as a person, electricity, sound waves, microbes, or even a supernatural being or force. My impression was that the Matses must have a concept of causation that is completely different from types of causation that I recognized. This interpretation would not be inconsistent with anthropologists' interpretations of causal thinking in other societies. For example, Needham (1976) 
a) Types of causation coded in active clauses:

\begin{tabular}{|l|l|l|}
\hline & Focused & Remote \\
\hline Unmediated & lexical causative & $\begin{array}{l}\text { lexical causative; } \\
-m e\end{array}$ \\
\hline Mediated & $\begin{array}{l}\text { lexical causative; } \\
\text {-me }\end{array}$ & $-m e$ \\
\hline
\end{tabular}

b) Types of causation coded in nominalizations:

\begin{tabular}{|l|l|l|}
\hline & Focused & Remote \\
\hline Unmediated & lexical causative-quid & $\begin{array}{l}\text {-anmës; } \\
\text {-an-quid; }\end{array}$ \\
\hline Mediated & $\begin{array}{l}\text { lexical causative-quid; } \\
\text {-me-quid }\end{array}$ & $\begin{array}{l}\text {-an-quid; } \\
\text {-me-quid }\end{array}$ \\
\hline
\end{tabular}

FIG. 2. - How different types of causation are (usually) coded by Matses causative constructions

maintained that the Kenyah of Borneo use a concept of (unmediated) « direct causation 》 that has no counterpart in Western society. Evans-Prichard (1937) argued that the Azande of Sudan have a theory of dual causation, wherein they attribute both natural and mystical causes to any event. Horton (1970) suggested that traditional African thought and Western science make different theory-based causal judgments, but make similar common sense causal connections. Others (e.g., Douglas 1975) take a relativist stance, suggesting that other cultures' ways of conceptualizing causality are equally valid to Western interpretations, but not understandable at all outside those cultures. And it has even been argued that the Trobriand Islanders have no concept of causation at all (Lee 1949).

All this might lead one to suppose that the type of causation coded by -ammës is characteristic of a very different mode of thought that considers unmediated remote causation events as likely as mediated ones. This view is discouraged by the fact that only a limited set of causal relations, those codable with -ammës, are sanctioned instances of unmediated remote causation, while productive usages of -anmës are for the most part restricted to curious situations in the non-Matses world. In my experience, unmediated remote causation is not proposed as an explanation for mundane events in every-day Matses life. Furthermore, I do not have to look beyond my own culture to find that unmediated remote causation composes at least a small part of folk models of causation. Black cats causing bad luck and justifying one's actions by saying, "The devil made me do it », involve remote causation with no readilyidentifiable intermediary. Similarly, Rozin et al. (1989) found that « backward contagion » (e.g., causing harm to an enemy using a lock of his / her hair), a mode of causal thinking that has no analogue in terms of known physical principles, is common in the everyday thinking of contemporary Americans. It seems that what makes the examples of Matses unmediated remote causation presented in this paper sound peculiar or implausible to me (and perhaps also the reader) is that these causal events, which 
cannot be observed directly, are generally based on culture-specific beliefs that we do not share with the Matses.

Talking of two aspects of causation separately, as in cognitive psychology, may help to elucidate the function of -ammës. One aspect of causation is the basic concept of causal relation and the other is causal attribution. According to White (1995), the best candidate for the first is the " generative relations concept ", the idea that causes actually produce or generate their effects, which may be a universal cognitive notion. By contrast, « Causal attribution is mainly a matter of seeking some object believed to possess the power to produce the effect in question ... " (White 1995, p. 5), a process that depends to a considerable extent on acquired beliefs and is thus subject to much across-culture variation. The notion that causation is not a single unitary concept is not consistent with linguists' characterizations of causation, but it has some explanatory power for describing causation in non-Western societies. Boyer $(1992,1995)$, for example, describes religious and « magical » causal beliefs as being no different from every-day knowledge about causation with respect to (universal) basic intuitive principles (i.e., their basic concept of causal relation), and to differ essentially only in causal attribution to magical objects, spirits, etc. And Morris et al. (1995) found that variation in Chinese and American causal explanations was based on differences in causal attribution influenced by culture-specific world views, but not to a difference in basic concepts about causal relation in general.

Although there is no grammar in Matses that codes causal relation exclusively (i.e., where a causal connection is established between the causer and the causee), when this grammar codes causative situations, it does not differ significantly from how causation is coded in other languages (Fleck to appear). The basic function of causer nominalizations, on the other hand, seems to be to code causal attribution. The interesting thing about the -ammës suflix, the only suffix that single-handedly codes causal attribution, is that it is not used for just any kind of causal attribution (-me-quid codes causal attribution more generally, but not exclusively), but codes causal attribution associated with the most mysterious kind of causation, unmediated remote causation. The fact that nominalizations with -anmës refer to events that most non-Matses would likely consider odd or implausible causal relations is perhaps not because the Matses have a different causal relations concept from people in other cultures, but rather result from culture-mediated attribution of causal properties to inanimate objects. By contrast, unmediated remote causation as a general principle of thought may be present at least tacitly in most cultures to some extent, even if they contradict explicit cultural beliefs about causal processes.

\section{CONCLUSIONS}

The findings of this study suggest that in addition to proposed cross-linguistic universals of causation, culture-specific notions of belief-based causal attribution should be elucidated to achieve an accurate linguistic description of causative constructions in a language. It seems probable that belief-based causal attribution sanctioning unmediated remote causation may be present in industrialized as well as traditional cultures. But the fact that Matses has a grammatical morpheme that codes exclusively these mystical causal attributions makes the Matses language typologically 
unusual. And it should be kept in mind that the morpheme -anmës does not simply code causal attribution to objects capable of unmediated remote causation, but -anmës additionally specifies other specific aspects like lack of volition and control, and undesirability and persistence of a caused state, which, unlike invisibility and mysteriousness, are not derivable from the « remote » plus « unmediated» features. The fact that so much rich semantic detail is coded in a single grammatical morpheme is unexplainable unless the concept is extremely salient to the culture in which the grammar evolved. This seems to be a case in point of the prediction of linguistic relativity theory that language embodies an interpretation of reality (Lucy 2000). Another prediction of linguistic relativity, that language can influence thought about reality (Lucy 2000), is instantiated by the Matses' general avoidance behavior and negative attitude toward all things named or regularly referred to with -anmës nominalizations. In fact, it could be argued that older, more conservative members of Matses society are (consciously or unconsciously) exploiting this association by using -anmës nominalizations to refer to non-Matses foods and products, steering other Matses speakers away from the national culture.

* Manuscrit reçu en mars 2001, accepté pour publication en juin 2001.

\section{NOTES}

1. First and foremost I would like to thank the Matses at Nuevo San Juan for hospitably sharing their insights into causation and for patiently teaching me about their language. Funding was provided by the Rice University Department of Linguistics Summer research grant. Pascal Boyer, Philip W. Davis, Philippe Erikson, Spike Gildea, and E. Douglas Mitchell provided helpful comments on earlier drafts of this paper.

2. The orthography used here is the practical orthography developed by Summer Institute of Linguistics personnel for Bible translation and pedagogical materials, which is the only writing system presently used by Peruvian Matses. The alphabet is phonemically-based and modeled after Spanish orthography. To produce a pronunciation that approximates Matses, words written in this orthography can be pronounced as if reading Spanish, with the following exceptions : $\ddot{e}$ is a high central unrounded vowel (iil); $c$ (spelled $q u$ preceding $e, \ddot{e}$, and $i$ ) is pronounced as a glottal stop word-finally and preceding consonants, and as [k] elsewhere; $d$ is pronounced as a flap between vowels, and as a [d] elsewhere; and $t s$ should be read as an unvoiced alveolar affricate. Word-level stress is (usually) on even-numbered syllables (counting left to right).

Morpheme gloss abbreviations :

$\begin{array}{llllll}\text { Agt } & \text { Agent } & \text { Erg } & \text { Ergative } & \text { Neg } & \text { Negative } \\ \text { Antpass } & \text { Antipassive } & \text { Gen } & \text { Genitive } & \text { Npast } & \text { Nonpast } \\ \text { Aug } & \text { Augmentative } & \text { Indic } & \text { Indicative } & \text { Nzr } & \text { Nominalizer } \\ \text { Caus } & \text { Causative } & \text { Inst } & \text { Instrument } & \text { Uncert } & \text { Uncertainty }\end{array}$

3. For example, English's many terms for types of motorized vehicles, or the Matses language's 47 lexemes for rainforest habitat types, 10 of which are non-polysemous monomorphemic terms (Fleck \& Harder 2000).

4. In this paper I use three semantic roles to talk about causative constructions: the causer is the participant that initiates the event and has ultimate control; the causee is the participant that is made to perform the caused event, and the patient is the person / entity that is ultimately affected by the causation event. In trivalent clauses, each of the three semantic roles is associated with a single argument ; e.g., in $B o b$ made Jim hit Joe, Bob is the causer, Jim is the causee, and Joe is the patient. In bivalent clauses, the causee and the patient may be conffated ; e.g., in Bob made Jim laugh, Bob is the causer and Jim is both the causee and the patient. 
5. It is interesting to note that other Amazonian tribes chew the heart of $H$. elegans to prevent tooth decay (Henderson et al. 1995), suggesting that this palm may produce a substance that causes a physical sensation motivating these inferences.

6. Interestingly, while the nine-banded armadillo (Dasypus novemcinctus) is tabooed, its almost identical but larger congener, the great long-nosed armadillo ( $D$. kappleri), is among the Matses' most prized game.

7. Recently I learned of two more lexicalized terms with -ammës from one Matses man, but $I$ have not had at chance to confirm them with other speakers. The terms are masedcammës " one that makes one's hair gray " and uspuanmës « one that makes one lazy. » The first term can be used to refer to a type of fish that if eaten can cause hair to turn gray, to discarded annatto pods that if touched can eventually turn one's hair gray, or to the bark of a tree called iwise, which can turn one's hair gray if it contaminates one's tobacco snuff. The second term is used to refer to both local species of capuchin monkey and to the red howler monkey, which can make a person lazy if he or she eats its flesh. These monkeys are tabooed for young people, and the cure is application of acate tree toad poison.

8. Although it seems unlikely that this ant actually bites sleeping people in the eye, I should acknowledge that I once woke up with a very red and sore eye, which the local Matses medicine man diagnosed as an $\ddot{e} u$ ant bite and treated most effectively with a leaf infusion of the « $\ddot{e} u$ ant's eye medicine » (a small epiphytic plant).

9. The application of acate tree toad poison to freshly burned skin has the ultimate positive effect of curing laziness and improving a man's marksmanship and hunting prowess. This hunting ability is transferred from an older, able hunter, to a younger man when the old man applies the poison to the young man's burns. However, the immediate effects, the sick feeling and the violent bouts of vomiting, are unwelcome and emanate from the poison, rather than the old hunter.

10. The suffix -an on intransitive stems does not increase the syntactic valence of a verb in other environments, so from where do the causative semantics emerge in -an-quid constructions? One could perhaps argue that a composite meaning arises from the specification that a state is being entered into (indicated by the inceptive / inchoative - $a n$ ) and that an agentive argument is involved (indicated by the agent nominalizer -quid), the implication being that one argument is causing a second argument to enter into a state. Although historical speculation is not a substitute for synchronic explanations, it is interesting to note the similarity in form between -an-quid and -anmës. Although there is no segmentable morpheme in Matses like -mës, the presence of an in -anmës leads one to question whether the origin of -ammës involved the inceptive / antipassive -an. In Shipibo-Konibo, another Panoan language, there exists a morpheme -mis, which appears to be an A nominalizer or an agent nominalizer [Valenzuela, personal communication]. So, it seems possible that -anmës became grammaticalized from the frequent combination of -an and an agent nominalizer that had a form like -mës. If -anmës indeed arose from frequent usage, this would be a third argument supporting the centrality of concepts coded by -anmës.

11. Lexical causatives are transitive verbs that commit the speaker to the belief that a caused event has been realized after, and is wholly dependent on, the causing event ex pressed by the verb (Shibatani 1976). This can be illustrated by contrasting similar verbs like English deceive and Matses muana « lie about / to ", where the English (causative) verb entails that a caused event was brought about, while the Matses (non-causative) verb expresses only an intention to do so.

\section{REFERENCES}

BOYER, Pascal, 1992. - «Causal thinking and its anthropological misrepresentation », Philosophy of the Social Sciences, 22, pp. 187-213.

1995. - «Causal understanding in cultural representations : cognitive constraints on inferences from cultural input $"$, in : SPERBer, Dan, David Premack \& Ann James Premack (eds.), Causal Cognition : A Multidisciplinary Debate, Clarendon Press, Oxford, pp. 615644.

Dixon, Richard M. W., 2000. - «A typology of causatives : form, syntax and meaning ", in : Dixon, R. M. IV. \& Alexandra Y. Aikhrnvald (eds.), Changing Valency : Case Studies in Transitivity, Cambridge University Press, Cambridge, pp. 30-83. 
Douglas, Mary, 1975. - Implicit Meanings: Selected Essays in Anthropology, Routledge, London.

Erikson, Philippe, 1994. - «Los Mayoruna », in : SANTos, Fernando \& Frederica Barclay (eds.), Guía Etnográfica de la Alta Amazonía, Volumen 2, Flasco-Sede/IFEA, Quito Ecuador, pp. 1-127.

Evans Pritchard, Edmond E., 1937. - Witchcraft, Oracles, and Magic Among the Azande, Clarendon Press, Oxford.

Fleck, David W., to appeat. - «Causation in Matses (Panoan, Amazonian Peru)», in : Shibatani, Masayoshi (ed.), The Grammar of Causation and Interpersonal Manipulation, John Benjamins Publishing Company, Amsterdam.

FLECK, David W. \& John D. HARDRR, 2000. — « Matses Indian rainforest habitat classification and mammalian diversity in Amazonian Peru », Journal of Ethnobiology, 20, pp. 1-36.

FLECK, David W., Robert S. Voss \& James L. PATrON, 1999. - « Biological basis of saki monkey (Pithecia) species recognized by Matses Indians in Amazonian Peru », International Journal of Primatology, 20, pp. 1005-1028.

Haiman, John, 1983. — « Iconic and economic motivations », Language, 59, pp. 781-819.

Henderson, Andrew, Gloria Galeano \& Rodrigo Bernal, 1995. — Field Guide to the Palms of the Americas, Princeton University Press, Princeton.

HorToN, Robin, 1970. - «African traditional thought and Western science », in : WiLsoN, Bryan R. (ed.), Rationality, Harper \& Row, Publishers, New York, pp. 131-171.

LAKoff, George, 1987. - Women, Fire, and Dangerous Things, The University of Chicago Press, Chicago.

LeE, Dorothy, 1949. — « Being and value in a primitive culture », The Journal of Philosophy, 46, pp. 401-415.

Lucy, John A., 2000. - «Introductory comments », in : NeImełer, Susanne \& René DiRveN (eds.), Evidence for Linguistic Relativity, John Benjamins Publishing Company, Amsterdam, pp. iv-xxi.

MALLE, Bertram F., to appear. - « Verbs of interpersonal causality and the folk theory of mind and behavior », in : SHIBATANI, Masayoshi (ed.), The Grammar of Causation and Interpersonal Manipulation, John Benjamins Publishing Company, Amsterdam.

Morris, Michael W., Richard E. NISBETT \& Kaiping PENG, 1995. — « Causal attribution across domains and cultures ", in : SPerber, Dan, David Premack \& Ann JAmes Premack (eds.), Causal Cognition : A Multidisciplinary Debate, Clarendon Press, Oxford, pp. 577-612.

Needham, Rodney, 1976. — « Skulls and causality », Man (n.s.), 11, pp. 71-88.

Romanofr, Steven A., 1984. - Matses Adaptations in the Peruvian Amazon, Ph.D. dissertation, Columbia University.

Rozin, Paul, Carol NemerofF, Marcia Wane \& Amy Suerrod, 1989. - « Operation of the sympathetic magical law of contagion in interpersonal attitudes among Americans", Bulletin of the Psychonomic Society, 27, pp. 267-370.

Shibatani, Masayoshi, 1976. - «The grammar of causative constructions : a conspectus », in : Shibatani, Masayoshi (ed.), Syntax and Semantics Volume 6: The Grammar of Causative Consiructions, Academic Press, New York, pp. 1-40.

Whith, Peter A., 1995. - The Understanding of Causation and the Production of Action : From Infancy to Adulthood, Lawrence Eribaum Associates, Publishers, Hove. 